\title{
Constraints in animal health service delivery and sustainable improvement alternatives in North Gondar, Ethiopia
}

\begin{abstract}
Authors:
Hassen Kebede

Achenef Melaku

Elias Kebede ${ }^{2}$

Affiliations:

${ }^{1}$ Department of Veterinary Clinical Medicine, University of Gondar, Ethiopia

${ }^{2}$ Department of Veterinary Pharmacy and Biomedical Sciences, University of Gondar, Ethiopia
\end{abstract}

\section{Correspondence to:}

Achenef Meleku

Email:

achenefmela@yahoo.com

Postal address:

PO Box 196, Gondar, Ethiopia

Dates:

Received: 24 Nov. 2013

Accepted: 21 May 2014

Published: 12 Nov. 2014

How to cite this article: Kebede, H., Melaku,

A. \& Kebede, E., 2014

'Constraints in animal health service delivery and sustainable improvement alternatives in North Gondar, Ethiopia', Onderstepoort Journal of Veterinary Research 81(1), Art. \#713, 10 pages. http://dx.doi. org/10.4102/ojvr.v81i1.713

\section{Copyright:}

(C) 2014. The Authors. Licensee: AOSIS

OpenJournals. This work is licensed under the Creative Commons Attribution License.
Poor livestock health services remain one of the main constraints to livestock production in many developing countries, including Ethiopia. A study was carried out in 11 districts of North Gondar, from December 2011 to September 2012, with the objective of identifying the existing status and constraints of animal health service delivery, and thus recommending possible alternatives for its sustainable improvement. Data were collected by using pre-tested questionnaires and focus group discussion. Findings revealed that $46.34 \%$ of the responding farmers had taken their animals to government veterinary clinics after initially trying treatments with local medication. More than $90.00 \%$ of the clinical cases were diagnosed solely on clinical signs or even history alone. The antibacterial drugs found in veterinary clinics were procaine penicillin (with or without streptomycin), oxytetracycline and sulphonamides, whilst albendazole, tetramisole and ivermectin were the only anthelmintics. A thermometer was the only clinical aid available in all clinics, whilst only nine $(45.00 \%)$ clinics had a refrigerator. In the private sector, almost $95.00 \%$ were retail veterinary pharmacies and only $41.20 \%$ fulfilled the requirement criteria set. Professionals working in the government indicated the following problems: lack of incentives (70.00\%), poor management and lack of awareness $(60.00 \%)$ and inadequate budget $(40.00 \%)$. For farmers, the most frequent problems were failure of private practitioners to adhere to ethical procedures $(74.00 \%)$ and lack of knowledge of animal diseases and physical distance from the service centre $(50.00 \%)$. Of all responding farmers, 58.54\% preferred the government service, $21.14 \%$ liked both services equally and $20.33 \%$ preferred the private service. Farmers' indiscriminate use of drugs from the black market $(23.00 \%)$ was also mentioned as a problem by private practitioners. Sustainable improvement of animal health service delivery needs increased awareness for all stakeholders and a well-regulated private service in order to mitigate the constraints apparent in the government service.

\section{Introduction}

Globally, agriculture provides a livelihood for more people than any other industry. Growth in agricultural production and productivity is necessary in order to raise rural incomes, to support the increasing numbers of people dependent on this industry (Upton 2004) and to meet the food and raw material needs of fast growing urban populations. Enhancing agricultural productivity contributes to industrial growth by providing cheap labour, capital investment, foreign currency and markets for manufactured consumer goods. Agriculture plays a key role in reducing poverty because most of the world's poor live in rural areas that are largely dependent on agriculture; food prices also determine the cost of living for the urban poor. Livestock provide over half of the value of global agricultural output and one third in developing countries (Upton 2004). Increased livestock production and higher self-sufficiency would reduce the need for foreign aid and increase gross domestic product as a result of the export of livestock and their products. Livestock production contributes to rural livelihoods, employment and poverty relief, integrating with and complementing crop production, acting as a savings bank and providing a buffer against risks (Sen \& Chander 2003; Upton 2004).

Poor livestock health services remain one of the main constraints to the development of livestock production in many developing countries. In sub-Saharan Africa, losses resulting from disease are estimated at $\$ 2$ billion per year, of which half is attributable to direct losses from mortality and the other half to indirect losses as a consequence of reduced growth, fertility and ability to work (De Haan \& Bekure 1991). These losses caused by animal disease are not simply restricted to lower outputs; in addition, disease prevents the introduction of livestock into certain areas (e.g. in Africa large tracts of land with high yielding potential are lost because of African trypanosomosis) and skin diseases, such as dermatophilosis, preclude the use of more productive animals, including crossbred dairy cattle, improved pigs and poultry breeds. Trade embargos are 
enforced by importing countries as a result of the presence of highly contagious diseases, creating another important bottleneck for the sector, reducing trade and the inflow of foreign currency. Furthermore, certain livestock diseases are zoonotic, which means that the control of animal disease is not only of economic importance, but also of social and political significance. Consequently, disease control services will continue to be an important factor in the development of the livestock sector (Cheneau, El Idrissi \& Ward 2004; Chilonda \& Van Huylenbroeck 2001).

As in many developing countries, most veterinary services in Ethiopia are currently provided by the government. Veterinary services, like many publicly provided livestock services to smallholder farmers in Ethiopia, are economically inefficient and, in many cases, may actually cost the government more than their value to the farmer. The pattern of budgetary allocations has resulted in the animal health public sector provision meeting less than $30 \%$ of demand (Cheneau et al. 2004; De Haan \& Bekure 1991).

The current global economic and political climate is forcing sharp reductions in government expenditure on statefunded services and a need for increased transparency and public accountability. The government of Ethiopia is making ongoing efforts to privatise many businesses in the service sector, but it seems that no priority is being given to veterinary services. It is now time to explore opportunities for a more decentralised, client-oriented, cost-effective approach to the delivery of animal health services (Silkin \& Kasirye 2002).

With the changing global economic situation, public services are being challenged to perform more effectively. Thus the concept of privatisation is finding wide acceptance as an alternative. Veterinary services are no exception to this trend. Privatisation means relying on society's private institutions rather than on those provided by the government. It is the act of reducing the role of government, or of increasing the role of private sector, in an activity or in the ownership of assets. Privatisation of veterinary services has become a necessity for several reasons. These include the reduction in financial resources, the small size of the budget allocated to the livestock sector, the difficulty experienced by the public sector in meeting the demands placed upon them, as well as the increasing inability of the government structure to absorb all the veterinarians and animal health assistants being trained (Tber 1995).

Privatisation in the context of the delivery of animal services relates to the transfer of activities, functions, responsibilities and property from the public to the private sector. It should be seen as a process of refocusing public sector veterinary services by devolving responsibilities, not merely as a means of reducing government expenditure. In planning for such changes, it is important to consider current and future projected consumer demand, disease epidemiology, changing livestock systems, socioeconomic growth, the availability of suitably qualified professionals, current and future infrastructure needs and the views of the existing clinical veterinary service. This will enable preparation of a sustainable programme that will help to facilitate effective privatisation of the animal health services (Mlangwa \& Kisauzi 1994; Sparagano 1999).

The objectives of this study were therefore to identify existing constraints to animal health service delivery and to recommend possible alternatives for sustainable improvement of animal health service delivery in the North Gondar administrative zone.

\section{Research method and design Study area}

North Gondar is located in Amhara National Regional State, bordering Sudan in the west, South Gondar and West Gojam in the south, Waghemra in the east and Tigray in the north. It encompasses different agro-climatic zones, including Kola (lowland), Woina Dega (midland) and Dega (highland). North Gondar zone harbours the north-western lowlands, which have huge agricultural potential, especially for livestock and cash crops such as sesame and cotton. Mixed farming systems (both livestock and crop production) predominate in the area.

The study was conducted in 11 districts (out of 22), namely Metema, Gendawuha Ketema Zuria, Chilga, Dembia, Gondar Zuria, Gondar Ketema, Lay Armachiho, Wegera, Dabat, Debark Ketema and Debark.

\section{Design \\ Questionnaire survey}

Three administrative units (locally called kebele) were randomly selected from total list of administrative units in each district using a simple random sampling method. A list of the farmers living in each administrative unit was taken from local development workers and systematic random sampling was used to select a total of five individuals. The list of farmers to be included in the study was dispatched to respective local agents before beginning the survey so that they could arrange time to come to centres during the schedule.

Using Thrusfield's (2005) derivation for sample size, the following assumptions were made and the number of individuals to be included was estimated. As the objective of the survey was more of a qualitative study, $10 \%$ error was inferred and, because no published work was encountered, $50 \%$ was used for prevalence of problems. The following formula was used:

$n=\frac{\mathrm{Z}_{\alpha^{2}} \mathrm{P}_{\exp }\left(1-\mathrm{P}_{\text {exp }}\right)}{\mathrm{d}^{2}}$

where $n=$ number of individuals to be included, $\mathrm{Z}_{\alpha}=$ confidence level (90\% $\left[Z_{90 \%}\right]$ confidence level was used), $P_{\exp }$ $=$ expected prevalence of farmers experiencing constraints in the service and $d=$ level of absolute precision. 
Furthermore, because of the seasonality of farm activities, a $50 \%$ response rate was expected. Therefore, to obtain 68 (50\%) responses, 136 individuals were needed: $136 / 11$ districts $=13$ farmers from each district. From each district, 3 kebeles were selected ( $13 / 3=4.3$ [i.e. 5] farmers per kebele). Recall papers were distributed for 15 farmers from each district, where a minimum of 10 and maximum of 15 farmers responded to calls for the questionnaire.

A structured and pre-tested questionnaire format was used to collect information from each district (total $=123$ ) and all veterinary practitioners involved in both the public $(n=20)$ and private sector $(n=17)$ available during the study period. The questionnaire was designed to assess the occurrence of common diseases in the area, the treatment regimens adopted when disease develops and the level of satisfaction with the existing animal health service delivery, including reasons for any dissatisfaction. During the questionnaire survey, it was attempted to correlate farmers' local perception of disease signs and symptoms with scientific contexts. For individuals in veterinary services (private and public), the methods used for routine diagnosis and commonly used therapeutic agents were also assessed. An assessment was also made of the costs, including professional services and therapeutic agents provided by private practitioners and the public service, together with any charges made.

\section{In situ observation of infrastructural setup}

A checklist (based on standards set by the regional bureau of agriculture) was prepared and both private $(n=17)$ and government $(n=20)$ animal health service delivery centres operating during the survey period were included, inspected and observations recorded for all available premises and facilities.

\section{Retrospective data collection}

Retrospective data over 5 years were collected from the agricultural district offices in order to assess budgetary and administrative constraints relating to planned activities and the ability to implement them with the available resources. The 5-year regional drug price record was assessed for the most common and routinely used drugs in public service delivery to characterise the trend. Average collective cost per year for each total unit of drugs considered was used to describe the trend.

\section{Discussions with district agricultural officers}

After the individuals in the public and private animal health service delivery sectors and farmers had been interviewed, the problems raised were summarised and forwarded to individuals in leading positions in the Ministry of Agriculture (MoA) at district, zonal and regional levels, whose views were obtained with respect to the existing constraints summarised from the survey and future prospects for the service, including options to improve it.

\section{Discussions with concerned regional bureaus}

After completion of the assessment survey, a checklist was also prepared for the regional bureau of agriculture, regional livestock agency, bureau of finance and economic development and the regional veterinary diagnostic laboratory. These checklists were targeted to assess the administrative and policy issues related to improvement strategies for the sustainable development of animal health delivery at the regional level. In the discussions, the regional laboratory and livestock agency, senior experts and middle-level professionals were involved. The existing constraints in terms of service delivery, options for improvement, opportunities and threats presented by privatisation, as well as what type of service to privatise were all raised for discussion.

Discussions with the regional bureau of finance and economic development and the regional bureau of agriculture, including directors, took place in order to evaluate the necessary policies for privatisation and the technical feasibility in terms of existing personnel and resource management.

\section{Results}

\section{Reported livestock diseases \\ Cattle}

Infectious and non-infectious diseases were described. Farmers included lumpy skin disease more frequently (46.34\%), whilst anthrax and gastrointestinal parasites were more frequently mentioned by professionals in the public and private services. Foot and mouth disease was frequently mentioned by both professionals and farmers.

\section{Small ruminants}

Small ruminants (sheep and goats) in the zone were also affected by several diseases. Sheep and goat pox was the disease most frequently mentioned by farmers and professionals working in the public sector. Gastrointestinal parasitism was mentioned most frequently by professionals working in the private sector.

\section{Poultry}

Farmers and professionals were also asked to list diseases that affect poultry. Newcastle disease was the most frequently mentioned, followed by coccidiosis, fowl pox and ectoparasites.

\section{Equine}

Of the diseases that affect equines, anthrax was most frequently mentioned, followed by mange, colic, African horse sickness and back sores.

\section{Small animals}

The most frequently mentioned disease of pets (dogs and cats) in the zone was rabies. Ectoparasites, internal parasites and flea allergic dermatitis were the most common problems indicated by farmers, government workers and private practitioners, respectively. 


\section{Current status of service delivery Existing practices by farmers}

Assessment of animal disease management practices indicated that $46.34 \%$ of the respondents had taken their animals to veterinary clinics (government) after initially trying local medicaments. Of the respondents, 19.50\% habitually administered modern medicines obtained from private or illegal sources themselves when their animals became sick (Table 1).

\section{Expenditure on veterinary services}

The estimated average costs incurred by livestock owners for animal disease related problems in different species per year are summarised in Table 2. A greater amount of money was spent on cattle than any other species.

\section{Existing practices in government service delivery}

Of the total number of public veterinary clinics visited $(n=$ 20 ), only $10 \%$ were known to use laboratory diagnostic aids for faecal egg screening. In none of the government clinics were either local or general anaesthetic agents evident, which indicates surgical procedures were not performed, or if they were, they were unethical, without pain management. The only antibiotics found in all of the veterinary clinics were penicillin $(+)$ streptomycin combination, oxytetracycline and sulphonamides. The anthelmentics found were albendazole, tetramisole and ivermectin and there were no antifungal agents. The disinfectants found in nearly $20 \%$ of government clinics were potassium permanganate and gentian violet. More than $90 \%$ of the clinical cases were diagnosed solely on the clinical signs or the history alone. In almost all sites, anthelmentics were given based on the history taken from the owner.

\section{Existing premises in government service delivery}

From the results of the visits, it was evident that all of the government clinics $(n=20)$ lacked appropriate facilities to restrain and handle clinical cases and they were not well equipped. A thermometer was the only instrument available in all the clinics. Only nine (45\%) of the clinics had a refrigerator, without any reserve power backups, implying less than $50 \%$ of clinics were able to handle vaccines or drugs that need cold chain storage. None of the clinics had a stereomicroscope for diagnosis of ectoparasites.

\section{Existing practices and facilities in private veterinary service}

Almost $95.0 \%$ of private service facilities were private drug retail shops owned by veterinarians and assistant veterinarians and, of those visited, only $41.2 \%$ were shown to fulfil the criteria set by the regional bureau of agriculture. Almost all drug shops handled pesticides (for control of crop pests) and antibiotics (for veterinary use) in the same dispensing area. In $2.0 \%$ of the drug retail shops, there were complaints about the sale of expired drugs and, in 30.0\%, clinical services for which they were not licensed were seen to be given during the survey.

\section{Reason for engagement in private service}

A question posed to private practitioners asked why they were engaged in private business. Nearly 35.29\% of them answered that they did so in order to acquire money to live; $23.53 \%$ answered 'for greater profitability'.

\section{Farmers' preference}

Of all responding farmers, 58.54\% preferred the government service, $21.14 \%$ liked both services equally and $20.33 \%$ preferred the private service. The reasons mentioned by farmers for their preference for either the public or private sector are listed in Table 3 and Table 4. About 47.22\% of farmers preferred government service because of cost. The farmers who preferred the private service attributed their preference to the availability of service whenever it was needed. The existing service delivery under the current animal health service was seen to be unsatisfactory, both in the private and public service systems, in terms of both quality and range. Many respondents were seen to use veterinary drugs without any veterinary supervision because of the distance from clinics or their lack of availability in the existing clinics.

TABLE 1: Accustomed practices undertaken by farmers to combat animal health problems.

\begin{tabular}{lll}
\hline Options practiced by farmers to combat animal health problems & $\begin{array}{l}\text { Number of respondents } \\
(\boldsymbol{n}=\mathbf{1 2 3})\end{array}$ & $\%$ \\
\hline Traditional medicine alone & 6 & 4.80 \\
Modern medicine on their own & 24 & 19.50 \\
Going to veterinary clinic $\dagger$ only & 35 & 28.40 \\
Traditional initially and then going to veterinary clinic & 57 & 46.34 \\
\hline Modern medicine on their own and then going to veterinary clinic & 3 & 2.44 \\
\hline
\end{tabular}

$\dagger$, Veterinary clinic indicates service givers with a varying degree of skills in veterinary practice.

TABLE 2: Average cost (in US Dollars) incurred for animal disease, as estimated by respondents.

\begin{tabular}{lll}
\hline Options practiced by farmers to combat animal health problems & Per case per year (\$) & Per household per year (\$) \\
\hline Cattle & 1.99 & 6.71 \\
Shoat (sheep or goat) & 0.95 & 3.96 \\
Equine & 1.01 & 2.49 \\
Camel & 0.29 & 0.85 \\
\hline
\end{tabular}

$n=123$. 


\section{Level of satisfaction}

Farmers were asked to indicate their level of satisfaction when they used the service, either in the government or private sector. About $37.7 \%$ of farmers were satisfied with the private service and fairly satisfied with the public service (Figure 1).

\section{Expectations for privatisation}

Possible impacts of privatisation for the future were assessed. Most (75\%) of the respondents said that privatisation would have a positive effect on veterinary service delivery in the zone. Reductions in the quality of service and job losses were also mentioned by respondents (Table 5).

\section{Constraints for veterinary service delivery Government veterinary service}

Constraints for veterinary service delivery in the public sector were related to management, clients (livestock owners) and professionals working in government. Some of the problems related to management were lack of awareness, shortage of budget and also the minimal attention given to the sector. Amongst client-related problems, distance from the service centre was most frequently (50\%) mentioned by respondents.
Lack of motivation either because of inadequate salary or financial resource availability was the most important problem conveyed by the professionals (70\%) (Table 6).

\section{Private veterinary service}

The constraints in private veterinary service delivery are listed in Table 7. Problems related to cost were most frequently mentioned by respondents $(40 \%)$. Failure to adhere to accepted norms and some unethical practices were also mentioned by some respondents (30\%).

\section{Retrospective assessment}

\section{Annual budget allocation in government service}

Comparison was made between the planned and allocated budget in the public veterinary service. No district had been satisfied during the last 5 years because the budget allocation was lower in all districts than the planned budget (Figure 2). There was also no indication of any increment in the annual government budget allocation to match the increase in drug prices; rather, there was a relative decline in the budget (Figure 3). Thus, an inverse relationship was observed between the annual budget allocation and the price of drugs (correlation ' $r$ ' $=-0.67$ ).

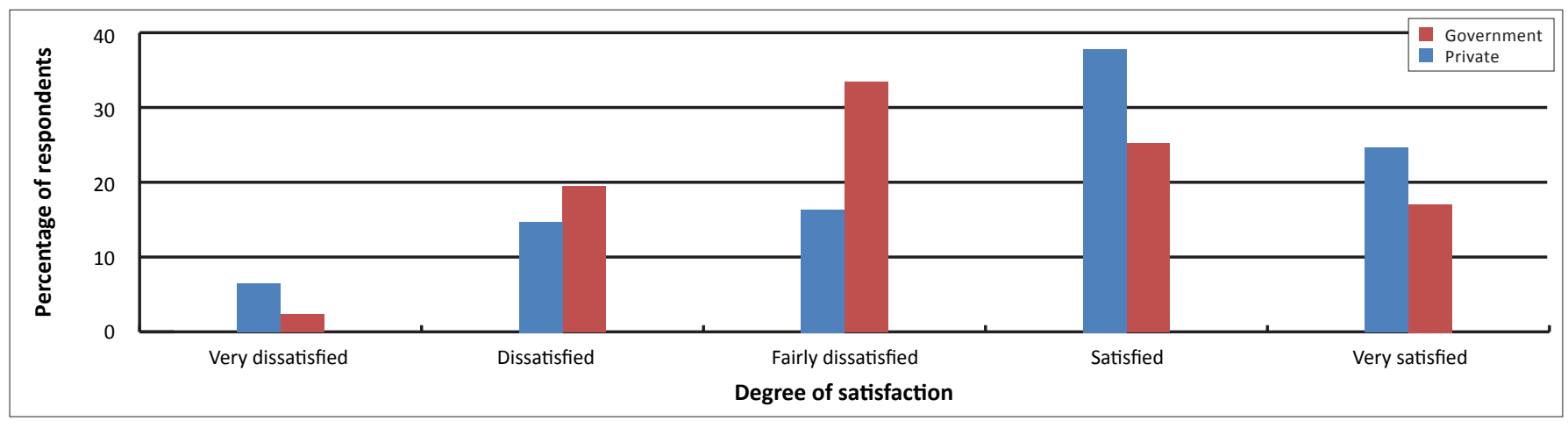

Source: Authors' own creation

FIGURE 1: Level of satisfaction of farmers with private and government veterinary services.

TABLE 3: Reasons indicated by farmers for preference of government service.

\begin{tabular}{lll}
\hline Reasons & Number of respondents $\dagger$ & $\%$ \\
\hline Government services are cheaper (less costly) & 34 & 47.22 \\
Government services are more effective & 10 & 13.89 \\
More qualified professionals are available in government services & 2 & 2.78 \\
Better quality of drugs in government services & 15 & 20.83 \\
Better diagnostic service in government facilities & 6 & 8.33 \\
The service is available nearby & 2 & 2.78 \\
Trust & 5 & 6.94 \\
Good cooperation by professionals & 1 & 1.39 \\
\hline
\end{tabular}

$\dagger$, Farmers may have given more than one reason.

TABLE 4: Reasons indicated by farmers for preference of private service.

\begin{tabular}{lll}
\hline Reasons & Number of respondents $\dagger$ & $\%$ \\
\hline Greater variety of drugs are available in private services & 4 & 16 \\
The service is always available & 11 & 44 \\
The service is fast & 7 & 28 \\
Farmers get what they wanted & 6 & 24 \\
The service is available nearby & 3 & 12 \\
\hline
\end{tabular}

$\dagger$, Farmers may have given more than one reason. 


\section{Annual physical plan execution report}

The average annual vaccination and execution of the treatment plan are shown in Figure 4 and Figure 5, respectively. The vaccination performance ranged from $50 \%$ to $75 \%$, whilst the therapeutic plan execution performace was greater than $70 \%$ during the last 5 years. However, the vaccination performance should also be evaluated based on the epidemiology of diseases and the number of animals in need of vaccination.

\section{Group discussion \\ District officials}

Representatives from district offices of agriculture as well as members of the animal health service team were involved in the group discussions undertaken at all assessment study sites. Problems experienced by individual farmers and animal health service personnel were presented and discussed and possible solutions were proposed. Problems raised by farmers regarding the government service included shortage of different drug types and absence of an accessible regular daily service from animal health assistants. Strengths included reliability of drugs when available and their value for money. People in the private animal health sector highlighted unfair price competition with government clinics, lack of implementation of laws on illegal drug circulation and lack of ethical practice by individuals working in adjacent services. The public sector raised issues around adequate staffing to support a dual mobile and ambulatory-based health service (during the mobile service delivery, a single animal health assistant is expected to cover three neighbouring peasant associations in rural service centres). Lack of incentives was also cited at almost all of the study sites. Engagement of public service delivery staff in non-animal health service activities was also raised in $60 \%$ of the group discussions; exceptions were Metema, Dembia, Debark and Chilga districts.

District representatives agreed partly on the questions raised by farmers and individuals engaged in service delivery. Solutions proposed included reinforcing and refreshing the illegal trade (drug) regulatory team, implementing the new regional livestock agency and sequential implementation of a regional plan for service cost recovery. From group discussions, the issue of privatisation was also encouraged as a solution.

\section{Regional bureaus}

From discussions with individuals from regional bureaus of economic development, it was evident that the government remained committed to its responsibilities for the delivery of public services for the benefit of the community. In this respect, the provision of an animal health service available

TABLE 5: Government service staff expectations of outcomes of privatisation schemes.

\begin{tabular}{lll}
\hline Government service staff expectations & Number of respondents $\uparrow(\boldsymbol{n}=\mathbf{2 0})$ & \% \\
\hline Reduce engagement in government service & 9 & 45 \\
Service will be improved & 15 & 75 \\
Loss of job & 3 & 15 \\
Reduce the quality of service & 4 & 20 \\
Proper supply of drugs on time as needed & 1 & 5 \\
\hline
\end{tabular}

$\dagger$, Respondents may have given more than one expectation.

TABLE 6: Problems in public veterinary service.

\begin{tabular}{|c|c|c|c|}
\hline Problem type & Problem as indicated by respondents & Frequency $(n=20) \dagger$ & $\%$ \\
\hline Problem as indicated by respondents & $\begin{array}{l}\text { Lack of awareness about importance of veterinary service } \\
\text { Shortage of budget } \\
\text { Less attention given to the veterinary service sector }\end{array}$ & $\begin{array}{l}12 \\
8 \\
1\end{array}$ & $\begin{array}{l}60 \\
40 \\
5\end{array}$ \\
\hline Client related & $\begin{array}{l}\text { Low perception } \\
\text { Cost of service } \\
\text { Distance from service centres } \\
\text { Farmers need anthelmintics without bringing their } \\
\text { animal(s) } \\
\text { Coming after several trials by themselves }\end{array}$ & $\begin{array}{l}8 \\
4 \\
10 \\
3 \\
1\end{array}$ & $\begin{array}{l}40 \\
20 \\
50 \\
15 \\
5\end{array}$ \\
\hline
\end{tabular}

$\dagger$, Respondents may have given more than one problem.

TABLE 7: Constraints in private veterinary service.

\begin{tabular}{|c|c|c|}
\hline \multirow[t]{2}{*}{ Problems } & \multicolumn{2}{|c|}{ Respondents $(n=20) \dagger$} \\
\hline & Frequency & $\%$ \\
\hline Failure to adhere norms (dose, expired drugs) and ethics by vets & 6 & 30 \\
\hline Failure to sterilise instruments & 2 & 10 \\
\hline Non-professional practices & 4 & 20 \\
\hline Failure to give good service without proper diagnosis & 3 & 15 \\
\hline Inadequate qualification, non-professional involvement & 2 & 10 \\
\hline High cost of service or drugs & 8 & 40 \\
\hline
\end{tabular}

$\dagger$, Respondents may have given more than one constraint. 
to the vast majority of the community, especially farmers, remained an important commitment, with the aim of providing a reliable service to address the deficits. The failure

to privatise agricultural support services in other African

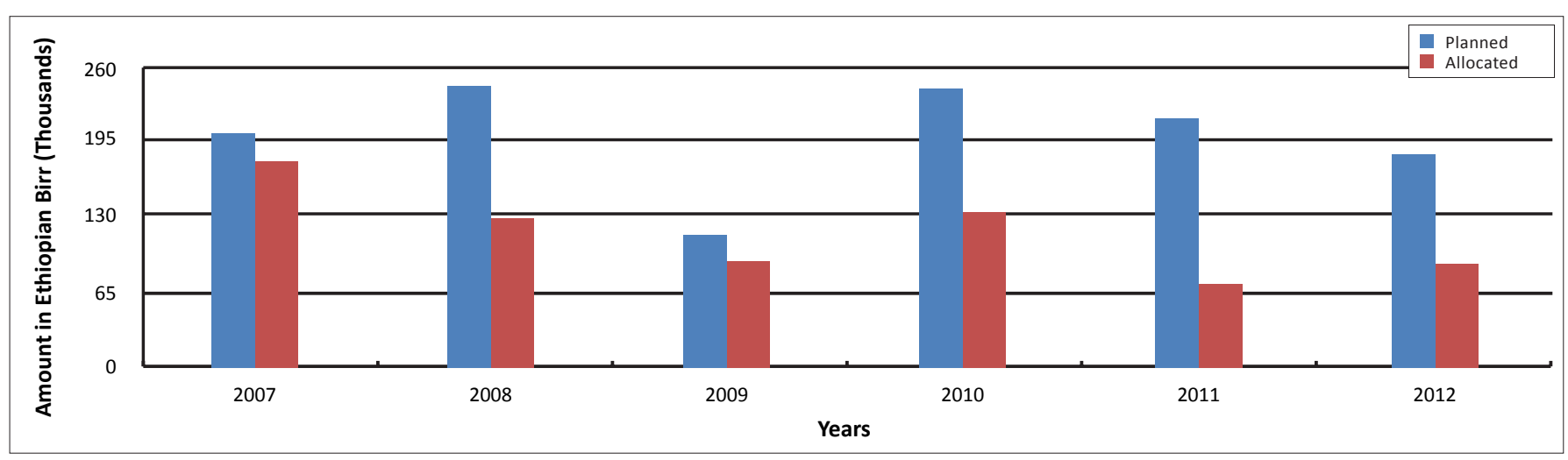

Source: Authors' own creation

FIGURE 2: Average planned and allocated budget in Ethiopian Birr, 2007-2012.

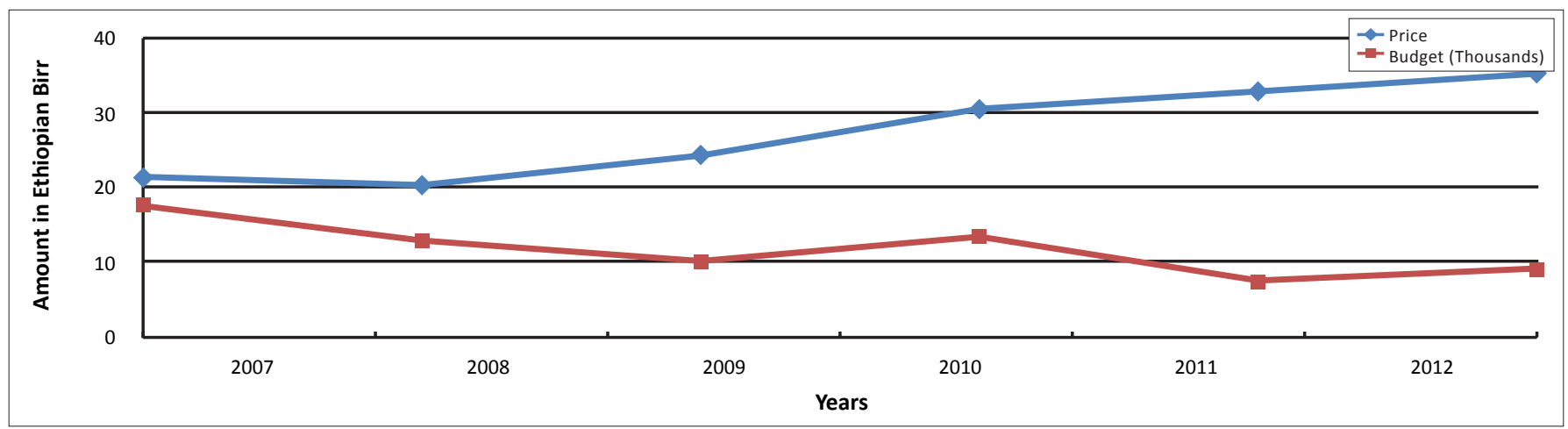

Source: Authors' own creation

FIGURE 3: The average price of drugs (in Ethiopian Birr) and the allocated budget, 2007-2012.

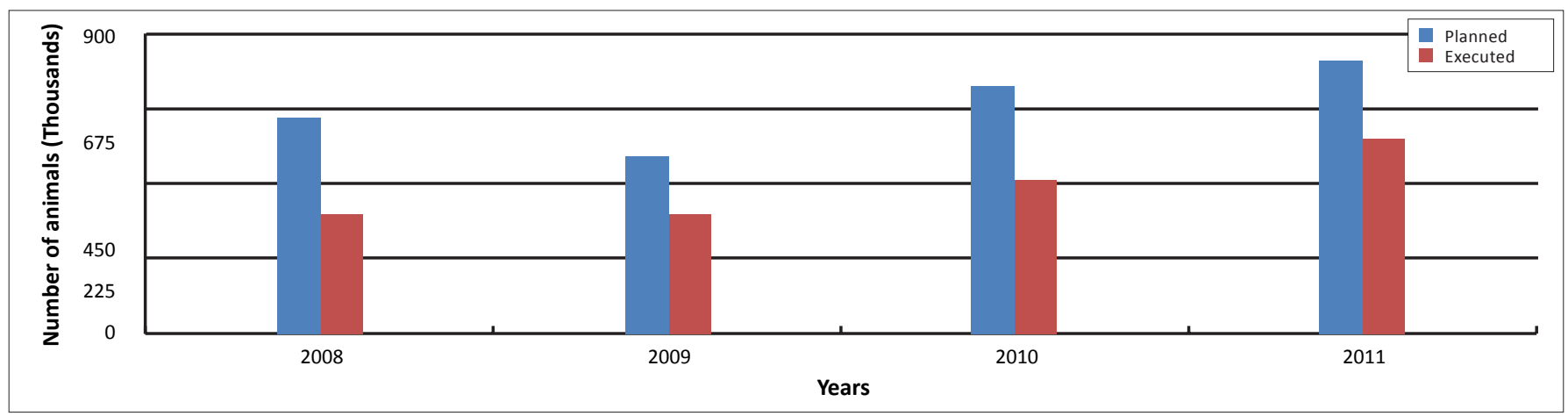

Source: Authors' own creation

FIGURE 4: Average vaccination plan versus actual execution, 2008-2011.

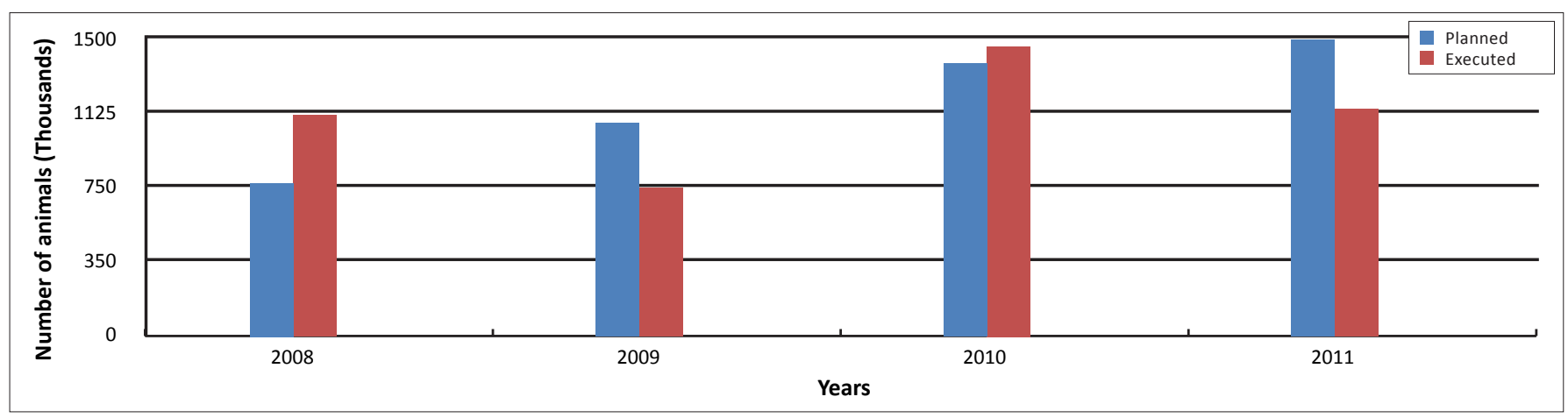

Source: Authors' own creation

FIGURE 5: Average annual animal health service plan and execution record, 2008-2011. 
countries was highlighted, suggesting that privatisation may be difficult to implement in Ethiopia. However, for the long term, privatising at least parts of the veterinary service cannot be overlooked. So far, policies to either support or impede privatisation have not been prepared at a regional level with specific reference to agricultural services. The absence of an agency to manage privatisation at a regional level was also raised.

During the discussion, the following constraints for animal health service delivery were listed:

- deficiency in budget allocation

- gaps in control of illegal drug circulation and implementation of ethical practices

- absence of adequate training and capacity building for existing government staff

- poor routine practice in procedures relating to animal health service delivery

- the need for existing professionals in public service to engage in non-professional duties and responsibilities in the office of agriculture

- problems related to paraprofessional practice (paravets)

- the low level of incentives to encourage individuals into the veterinary service - basic pay and related allowances

- poor support services for animal health

- shortage of laboratory facilities, including reagents and materials

- poor networking with other stakeholders - university faculties and multiplication centres

- free service delivered by the government service and constraints upon the necessary facilities, diagnostic tools, prophylaxis and treatment.

The option of privatisation was raised in all of the group discussions. Pre-requisites included the implementation of an appropriate code of practice in the public and private sectors, a change in attitude of both farmers and professionals towards a quality service and the establishment of cost recovery for government services. Concerns regarding privatisation of the service were also raised with respect to business drivers becoming predominant before the proper implementation of a code of practice to ensure that strong ethical values are maintained, in order to change attitudes, so that delivery of a quality animal health service to farmers could be achieved.

The issue of what to privatise was also discussed. There was strong debate about whether to recommend that the vaccination service should be handled by private service or not. The issue of covering the costs of transboundary disease vaccination by the MoA and difficulties with the requirement for cold chain maintenance were also discussed. It was then concluded that, although it may be difficult at the initial stage, providing a quality private service could help solve the problems and that the MoA can play a role in its facilitation.

\section{Discussion}

\section{Disease epidemiology}

The North Gondar administrative zone comprises highland, upland and lowland agro-ecologies. These diverse agro- ecological zones create an ideal environment for the prevalence of a variety of animal diseases. Government and private sector professionals and farmers described several livestock diseases. These included major viral, bacterial, parasitic and metabolic diseases affecting cattle, sheep, goats, horses, cats and dogs. The presence of various animal diseases in the zone was also reported by Tegegne et al. (2009). These diseases result in important economic losses by either directly killing animals or indirectly by reducing their productivity.

\section{Status of existing service}

The existing service delivery under the current animal health system was considered to be unsatisfactory in both private and public sectors in terms of quality and effective widespread delivery. From personal observation of respondents, a considerable number of veterinary drugs were being administered without veterinary supervision because of remoteness of clinics or non-availability of adequate services in existing clinics. Willingness to pay for a quality service was also assessed for general clinical examination, castration, caesarean section, normal delivery, both open and closed castration as well as wound management. Nearly $52.2 \%$ of responding farmers were willing to pay suggested acceptable prices. The remaining respondents would not volunteer acceptable prices because they felt that services should be provided by the government or that the service deliverer should determine prices. Respondents in areas of greater economic potential emphasised the value of a quality service rather than being influenced by price. The indicated acceptable prices were comparable to regional prices studied for the implementation of cost recovery under the MoA in selected milk shed areas of the region (Swedish International Development Authority 1994).

\section{Options for service delivery improvement}

Privatisation of veterinary services was preferred as a possible solution for improving animal health service delivery by respondents in the present survey. Similar ideas put forward by Sen and Chander (2003) suggested privatisation of veterinary services as one strategy for providing an efficient veterinary service. Cheneau et al. (2004) also reported on the improvement in veterinary services in developing countries as a result of privatisation. Consequently, many countries in the world have started to implement or have already implemented privatisation. The availability of drugs and their use in animals are significantly higher in countries that have privatised veterinary services and drug supplies (Cameroon, Central African Republic, Côte d'Ivoire, Ghana, Kenya, Mali and Senegal) (Sen \& Chander 2003). As a consequence, many African governments are moving to privatise their veterinary services. The government of Zambia is also encouraging free competition amongst veterinarians (Mlangwa, Chilonda \& Pandey 1997).

Despite successes in different parts of the world, privatisation is not necessarily free from problems. Some of the respondents 
in this research suggested that the quality of the veterinary service might actually be reduced by privatisation. Private practitioners may fail to adhere to norms and professional ethics. They may also concentrate in and around urban areas, leaving remote rural communities isolated (Cheneau et al. 2004; Sen \& Chander 2003). They may also focus solely on profit rather than providing effective quality services.

In Ethiopia, there is a free market ideology and there are policies that promote the private sector. There has been some progress in veterinary services. Almost all importation and distribution of veterinary drugs is handled by private companies. Any veterinary professional can obtain a license and set up in private practice. In any district, there are one or more private veterinary pharmacies and, in big towns such as Gondar, there are private veterinary clinics. Despite this, the process of transferring decades of a state-monopolised service into the private sector is still slow. Accordingly, no progress has been made in delineating public and private responsibilities with respect to animal health service delivery and in promoting private practice. Private veterinary practice has been promoted under the European Union-funded PARC programme. In 1993, a condition of continued funding was that this programme should show greater progress and the most recent report from the Veterinary Privatisation Promotion Office showed that compared with other countries considerable advances have indeed been made. The report also showed that between 1995 and 2001, the percentage of private clinics rose from $6.0 \%$ to $14.7 \%$ of the total and the percentage of private health posts from $1.0 \%$ to $6.5 \%$ (Silkin \& Kasirye 2002).

Livestock owners do spend some money on veterinary services. The value presented in Table 3 is a rough estimate, as most farmers do not keep records. However, it does indicate the willingness of farmers to pay for some veterinary services. The sustainability of a private service depends on the profitability of livestock owners. The types of production systems, livestock densities and the market price of the animals all impact upon profitability for the private practitioner (Umali, Feder \& De Haan 1992). There is resistance in the public sector to charging real costs (full cost recovery) for the services it provides. It is, however, essential to do so if the private practitioner is to be assured of an adequate income and if the economy is to grow.

The government service is confronted by many problems. Respondents mentioned inadequate availability of instruments, lack of awareness, shortage of budget and insufficient government attention to the sector, resulting in an inability to maintain full service provision. The government budgets have not kept pace with the increased livestock population and price of drugs. Each year, no satisfactory budget has been allocated to the districts. The presence of significant constraints in the government gave rise to concerns about the efficiency and efficacy of the public sector veterinary service and the diverse demands of farmers have led to a search for alternative ways of providing the service. Privatisation could be the solution to these problems (Sen \& Chander 2003).

\section{Recommendations}

Based on the conclusions from this study, the existing constraints for veterinary service delivery could be ameliorated using the following recommendations:

- Increased privatisation, with a continuing reduced but properly resourced government service. The benefits need to be demonstrated to farmers in livestock production so that there is an obvious working partnership, which can be seen to be beneficial in terms of good disease control and improved productivity through ready access to a robust service. This needs to include an outreach service for ongoing education of the farming community.

- The government service delivery should cease to provide a free service and implement cost recovery programmes, so that private veterinary service can be encouraged to play its role in animal health service delivery with appropriate ethical standards.

- Strategies developed for privatisation of veterinary services should underline the possible pitfalls for their sustainable implementation.

- Policies, rules and regulations regarding privatisation of veterinary services need to be clearly established in advance.

- Implementation of privatisation programmes needs to be phased, monitored and demonstrated to work.

- If the government prefers to continue with its commitment to the existing level of public service, then appropriate resources must be made available, including recruitment and outreach education, to ensure the expected quality of service delivery and the understanding of disease control measures by the farming community.

- The privatisation process requires initial seed money for those would be private practitioners. To address this case, the saving and credit associations and the government structure must make a deal and devise a strategy to make credit available and accessible.

- The non-governmental organisations working in livestock productivity should also consider supporting the privatisation procedure and associated seed money issues as one area of focus to enable privatisation to be a working platform in improving animal health and productivity.

- Inclusion of entrepreneurship and business management courses in the veterinary medicine curriculum needs to be considered, or else arrangements should be made to offer such courses after graduation to let the new graduates consider providing private veterinary service as an alternative job market and to ultimately survive and thrive in it.

\section{Conclusion}

According to this study, the range of endemic diseases and the severity of their impact on livestock production were perceived to be critical by professionals in government service and the private sector, as well as the farming community. The most important diseases that were included in the World Organisation for Animal Health's former List A 
of notifiable diseases were highlighted because of their wide distribution and frequency of occurrence: foot and mouth disease, lumpy skin disease, peste des petits ruminants, Newcastle disease, African horse sickness and contagious caprine pleuropneumonia. The most frustrating disease of zoonotic importance, rabies, was also highlighted because of its occurrence in all study areas.

The status of the veterinary service is in its infancy in terms of both widespread coverage and standardised service provision in both the government and private sectors. There was a view that the budget allocation was insufficient to provide quality service delivery that is accessible to the whole community. The yearly budget allocation does not match the requirements for resources to spend on trained personnel, equipment, facilities and drug price inflation, thus precluding implementation of the 5-year action plan. The attitude of officers in the government sector towards a privatised veterinary service seemed to be favourable in terms of encouraging the private sector to be involved, rather than a total service transfer from the public to private sector. A considerable proportion of professional respondents from study districts were somewhat pessimistic about the current trends in the public sector if they continue and made suggestions for service improvement.

In addition, respondents also attributed constraints for the quality of service delivery from the government veterinary service to management-related constraints in resource allocation, shortage of the required tools and facilities and a lack of awareness and perception of the needs of livestock owners. Private service was judged to be constrained by problems related to the subsidised government service, gaps in implementation of legal and ethical practices, absence of institutions for securing the finance required to start businesses, lack of trust by farmers in a private service, as well as an unwillingness or inability to pay for services delivered. Deficiencies in access to services by farmers have also led farmers to use modern veterinary drugs as well as traditional remedies without veterinary supervision.

The regional bureaus of agriculture as well as the bureau of finance and economic development have studied the issues relating to privatisation of the veterinary service. Some officials maintained that the service provision should be a responsibility of the government. Others have raised the point that there is no particular policy directive that would either preclude or facilitate the implementation of a private veterinary service. The only regulations related to private veterinary practice were encountered in the regional livestock agency. Consequently, from the observations made to date, a slow step by step engagement with a privatised service could be a solution to the future sustainable management of the animal health service.

\section{Acknowledgements Competing interests}

The authors declare that they have no financial or personal relationships which may have inappropriately influenced them in writing this article.

\section{Authors' contributions}

H.K. (University of Gondar) was the project leader who formulated the primary proposal, was involved in data collection and writing of the manuscript. A.M. (University of Gondar) was instrumental in data collection and analysis. E.K. (University of Gondar) was involved in data collection and editing of the final draft.

\section{References}

Cheneau, Y., El Idrissi, A.H. \& Ward, D., 2004, 'An assessment of the strengths and weaknesses of current veterinary systems in the developing world', Revue scientifique et technique, Office international des Épizooties 23(1), 351-359.

Chilonda, P. \& Van Huylenbroeck, G., 2001, 'A conceptual framework for the economic analysis of factors influencing decision-making of small-scale farmers in animal health management', Revue scientifique et technique, Office international des Épizooties 20(3), 687-700.

De Haan, C. \& Bekure S., 1991, Animal health services in sub-Saharan Africa: Initia experiences with new approaches, ALPAN network paper 29, International Livestock Centre for Africa, Addis Ababa.

Mlangwa, J.E.D., Chilonda, P. \& Pandey, G.S., 1997, 'Veterinary ethics in the liberalized market: The Zambian environment', Revue scientifique et technique, Office international des Épizooties 16, 739-745.

Mlangwa, J.E.D. \& Kisauzi, D.N., 1994, 'Systems approach to animal health services delivery in sub-Saharan Africa - the case of privatisation', Revue scientifique et technique, Office international des Épizooties 13, 673-685.

Sen, A. \& Chander, M., 2003, 'Privatization of veterinary services in developing countries: A review', Tropical Animal Health and Production 35, 223-236. http:// dx.doi.org/10.1023/A:1023343429498

Swedish International Development Authority, 1994, 'Study on cost recovery of veterinary services provided by Ministry of Agriculture in selected districts of Amhara region', SIDA, Bahir dar.

Silkin, T. \& Kasirye, F., 2002, Veterinary services in the Horn of Africa: Where are we now? A review of animal health policies and institutions focusing in pastoral areas, Community-based Animal Health and Participatory Epidemiology Unit, Pan African Programme for the Control of Epizootics, viewed 15 April 2013, from http://sites.tufts.edu/capeipst/files/2011/03/Silkin-Kasirye-pdf-version.pdf

Sparagano, O., 1999, 'Privatisation of animal health services in the tropics', Tropical Animal Health and Production 31, 191-192. http://dx.doi. org/10.1023/A:1005173731087

Tber, A., 1995, Privatization of veterinary practice: Evaluation of the experience of African countries in this field, Mimeo, Memphis.

Tegegne, A., Mengistie, T., Desalew, T., Teka, W. \& Dejen, E., 2009, 'Transhumance cattle production system in North Gondar, Amhara Region, Ethiopia: Is it sustainable?', working paper 14, Improving Productivity and Market Success of Ethiopian Farmers Project, International Livestock Research Institute, Addis Ababa.

Thrusfield, M., 2005, Veterinary epidemiology, 3rd edn., Blackwell, Edinburgh.

Umali, D.L., Feder, G. \& De Haan, C., 1992, The balance between public and private sector activities in the delivery of livestock services, World Bank discussion paper 163 , World Bank, Washington, DC.

Upton, M., 2004, The role of livestock in economic development and poverty reduction, PPLPI working paper 10, Food and Agriculture Organization, Rome. 